\title{
Stress Levels of College Students: Interrelationship between Stressors and Coping Strategies.
}

\author{
Ms. Lakyntiew Pariat, Ms Angelyne Rynjah and Ms Joplin, M G Kharjana
}

\section{Introduction}

College life is one of the most scintillating and memorable experiences in an adolescent's life. It is in college that an adolescent enjoys the vibrant environment, the company of friends and the various academic and co-curricular activities, which enriches nurtures and henceforth prepares the adolescent for adulthood.

Looking from a closer perspective, the college student's encounters a number of challenges in his day to day life, therefore the whole idea of an exciting and vibrant college life is unveiled by these challenges which in turn contribute to stress and if not dealt with can only escalate and hamper their academic performance, emotional and social well-being.

College students are exposed to a considerable amount of stress, which necessitate successful and constantly changing coping strategy. These stressors include internal and external pressures exerted by the environment to thrive and succeed, overcome economic hardships, worries about vague futures, societal problems and opportunities. College students often meet their future partners in college, hand in hand they also require preparation and focus to perform well in home works and tests in various subjects and disciplines, consequently they very often face inconsistent outcomes. Therefore ineffective coping can lead to anxiety, drinking problems, depression and a multitude of other mental health problems amongst college students. The issue of stress among college and university students has been in focus for several years. Elevated stress levels amongst students can result in a decline in the academic accomplishments, and can affect both the physical and mental health of students. Therefore, studies on coping with stress will have a significant impact in higher education. (Scott, 2009)

Despite the fact that the news broadcast college preparatory high schools as the main sources of pressure and stress, more studies are needed as not many experimental studies have been conducted with students in these settings. (Conner et al.2010)

In recent times, students encounter all kinds of stressors, such as that of excelling in academics, vague future and problems associated with adapting into the college environment. The learning abilities and academic outcomes of these students are affected when they encounter challenges such as social, emotional, physical and family problems. (Fish \& Nies, 1996, Chew et al., 2003) According to Feld 2011, the most important stressors encountered by students include high individual and external expectations, and stressful surroundings as well as academic motivators such as academic tasks, ranks and college recognition. Students believe that they would practice an improved way of life if these challenges were removed.

Babar et al 2004 found out that the most dominant stressors were that of academics and examinations. The subject of academic stress and college students has been in the limelight for several years. During every semester, at specific periods college students experience pressure due to academic engagements and responsibilities, economic hardships and improper time management skills. Health and academic accomplishments can both be hampered if stress levels are very high and if stress is negatively perceived. (Campbell \& Svenson, 1992).Womble, 2003 studied various factors that can weaken a student's academic achievements. These factors included societal activities, job demands or romantic relationships which can take away valuable time.

In India, the factors responsible for the outcomes such as emotional stress and internalized problems are due to elevated levels of academic and social stress. (Verma et al. 2002, Krishnakumar et al. 2005, Lai \& Wong 1992). While students stress has often been linked in the literature to family problems, similar results were found in studies by other researchers that students learning ability and academic accomplishments were affected by family problems(Fish et al 1996; Chew et al, 2003)

Social support from the university, family, friends and mentors create an enormous impact on student's achievement and performance. Likewise, emotional, academic and financial aids are incredible factors which ascertain the success of college students. College life can be stressful and alter the life experience of a student, it is therefore vital to be in the company of family and friends while being in college. (Trockel et al. 2000) Shaikh et al 2004 also reports that relationship problems both at home and in college often contributes to stress. As stated by Greenberg (1996) making new friends is one of the causative factors of stress amongst college 
students. Besides making new friends, it is often seen that transforming and building new friendship is a stressful situation highly related with college life.

An individual's self-esteem is enhanced through academic excellence and accomplishment.ills, (1991) states that academic achievement is influenced by self- esteem. Studies conducted by Dennis et al., (2005) and Nicpon et al., (2006) clearly determines that students who are socially inactive tend to be more isolated, attain low grades and are more at risk of withdrawing from college. A decline in the academic performance and adjustment is seen among students who are lonely and socially inactive in college thus making them unable to utilize the social resources available in the campus.

Pinto et al. 2001; Ross et al. 1999 and St. John, 1998, documented a decline in academic performance as a result of financial stress. However, Mehta, et al., (2011) suggested that financial stress is not the only determining factor of poor academic performance.

Investigation carried by Patel \& Greydanus (1999) exhibits adolescent stage to be a crucial period where substance use primarily develops. As a consequence of peer pressure, college recognition and accessibility of substances (alcohol, drugs, tobacco such as cigarettes and gutkha), substance abuse by students is mainly due to academic stress. As reported, nearly 5500 children and adolescents in India, begin usage of tobacco products daily, with a majority who initiate substance intake before 18 years and a few as young as 10 years old.

The major purpose of substance usage as affirmed by Lukoye et al., (2011) were mainly peer pressure, experimentation, and de-stressing. The incidence of substance abuse mainly smoking and alcohol is very high among students in economically backward countries. Poor academic performance, low self esteem, bonding difficulties with parents, lack of moral and spiritual values, sensation seeking and early initiation of substance use as a result of perceived peer pressure are the dominant risk factors responsible for high substance abuse among the youth. (Otieno \& Ofulla, 2009)

reenberg and Valletutti, 1980, state that a good psychological balance on the part of person is an effective tool to deal with stress. The strategies to tackle stressful crisis are referred to as coping mechanisms; which include the, behavioural, physical, external factors, emotional, spiritual and cognitive strategies. ((Lazarus 1999; Lazarus \& Folkman 1984; Everley et al. 2002; Westen 1999; Tix et al. 1998). Positive coping strategies relieves stress and was found to be beneficial in the long run, unlike negative coping which may ease stress for a short period of time (eg. Use of alcohol or drugs, or withdrawal from social interaction), but prove to be harmful and affect both the physical and mental health. (Everley et al. 2002). Good coping skills are likely to lower the stress levels whereas negative coping increases stress (Lazarus 1999).

Coping techniques such as proper utilization of time, involving in leisure related activities, optimistic appraisal and support from friends and family often relieves stress in students (Blake \& Vandiver, 1988; Mattlin et al., 1990). Leisure and exercise relieves stress, motivates and provides directions and increases proficiency in college students (Ragheb \& McKinney, 1993). Different coping methods such as finding help, solving problem, leisure, exercise, cognitive-restructuring, and a sense of security were found to be beneficial (Donaldson \& Prinstein et al., 2000).

According to Kadapatti \& Vijayalaxmi 2012, stressors like academics; social, emotional and financial has an impact on the academic achievements of a college student. Results of an Indian study revealed that factors associated with curriculum and workloads combined with economic deprivation are accountable for academic stress. Low academic achievement of some students can be a consequence of improper time management, economic hardships, lack of sleep, and societal engagements .This is also seen in students with children. (Maheshwari \& Deepa 2013)

Researchers have given a lot of emphasis on the issues of college going students, an important area of study being stress and how students cope with it. The studies above indicate that stressors like social, emotional, financial conditions at large affect the academic performance of students although academics is a stressor all by itself. After a thorough literature review very rare studies were found to be conducted in Shillong, Meghalaya on the topic hence the present study "Stress levels of college students: Interrelationship between stressors and coping strategies" is therefore conducted with the aim of exploring and confirming the stressors and how students deal, behave or cope with these stressors in this part of the region.

\section{Participants}

\section{Materials and Methods}

Participants in this study were college students enrolled in five reputed colleges of Shillong city. Degree students who were pursuing their studies in different streams namely Arts, Commerce, Science and who were in between the age group of 19-23 years of age and also students below 19 years and above 23 years were selected. $53.1 \%$ of the participants surveyed were in the age group of 20-22 years. 50.1\% were males and $49.9 \%$ were females showing a normal distribution between both males and females. 
Stress Levels of College Students: Interrelationship between Stressors and Coping Strategies.

Measures

A well structured questionnaire was framed rather than relying only on validated scales so that the survey could explore the various contributory factors and stressors which are not included in the standardized scale.

Validated standardized scales were included in the survey to ensure that the results were psychometrically reliable and valid. The standardized scale was chosen for its relevance to the college student population and to determine the stress level of the students.

\section{Questionnaire}

The self structured questionnaire includes three sections. The first section comprising of demographic information, the second section is a set of questions on academic, emotional, social, and financial stressors and the last section includes the statements on positive and negative coping.

Demographic Information: This section included general questions on the age, gender, course and year of study, type of accommodation, type of family, marital status of parents and the interviewee, number of siblings, and demographic and educational qualification and occupation of parents.

Contributory Factors to Stress: A series of questions on academic, social, emotional and financial stressors were presented and students were asked to indicate to what extend these factors were stressful or cause stress.

\section{Students Stress Scale}

In this section students were asked to complete the students stress scale (Akhtar, 2004).

\section{Psychometric properties of the validated scale}

The students stress scale confirms the dominant stressors in the current scenario. The scale includes varied questions on various situations in the day to day life of a student. The questionnaire was prepared using the five point Likert scale. The questions have five options, the options were scored from one to five, and i.e. from never to always. There were 80 items in the preliminary questionnaire. The choices were always, often, sometimes, rarely and never. After the item analysis was done, 51 items were selected as they were found to have good discrimination value. The method given by Davis (1949) was used for item analysis.

Reliability: Two types of reliability are important for evaluating scale. First internal consistency or coefficient alpha reliability was estimated. This coefficient alpha was established 0.78 and is significant at 0.01 level of significance.

The second test-retest reliability reflects stability over time. The test-retest reliability of the scale was 0.71 .

Validity: The scale has construct validity of 0.72 . Validity was established by using test developed in India to measure Life Stress Scale for students by Agarwal and Naidu.

The scoring of the test: There are 51 items in the Student Stress Scale and each has been provided with 5 options, which are Always, Often, Sometimes, Rarely and Never. These five options have been scored in order to get mathematical result from the test. The five point rating scale has been followed and hence starting from Never to Always score is given from 1-5. So that the strength of the indicator i.e., its high occurrence is shown by a large sum and vice versa. There are some negative items which have been scored from Never up to Always which is given 5-1. The maximum score on Student Stress Scale would be 255 and minimum 51. Therefore, the range of Student Stress Scale is 51-255. A very high score above the $75^{\text {th }}$ percentile is found to be very high level of stress. Moderate levels of stress above $50^{\text {th }}$ percentile need immediate attention. Low score below, $25^{\text {th }}$ percentile is found to be low level of stress.

\section{Procedures}

Prior to the conduct of the main study a pilot study was undertaken in order to evaluate the questionnaire and improve it. Permission and approval from the institutions and the participants was sort before the conduct of the study. Participants were briefed in their respective classrooms regarding the questionnaire and the scale and confidentiality of the data was assured to the participants. Undergraduate students both males and females were included from each college by convenience sampling method. A total of 600 questionnaires were distributed, out of which 537 completed the questionnaire in presence of the investigators of the study so that doubts raised by the participants could be clarified.

\section{Statistical Analysis}

The data was analyzed by using SPSS software where the frequency and percentages, t-test and correlation analysis was found out for the different parameters. These analysis were done in order to interpret 
the demographic characteristics, level of stress among the college students, the behavioural mechanisms and coping strategies adopted by them.

\section{Results and Discussion}

Demographic Information: The demographic information on the age distribution, gender, course and year of study, accommodation, type of family, marital status, literacy rate of parents was collected and it was found that $55.1 \%$ of the participants resided in their own house during the course of study. This is mainly because participants are native to Shillong city. The remaining participants studying in Shillong were either residing in the hostel or rented house who belonged to other North Eastern States. Majority (57.5\%) of the participants surveyed belongs to the nuclear family. Out of the total 537 participants 23.5 per cent females and 21.9 per cent males had 5 or more than 5 siblings. Married students included a minority of 1.5 per cent males and 1.7 per cent females. Only 0.4 per cent males and 0.2 per cent females were Divorced / Separated. Majority $(90.3 \%$ fathers and $85.9 \%$ mothers) of parents were literate. These results well establish that high literacy rate predominates among the parents. Shillong being the capital of Meghalaya and famous for its educational institutions, high literacy rates prevails among the population of Shillong and this is well reflected in the results.

Academic Stress: The academic stressors included were family expectation, teachers' expectations, competition with other students and excessive course work or workload. Of all the academic stressors, family expectations (52.7\%) and teacher expectations (32.4\%) contributed the most (i.e. $52.7 \%$ and $32.4 \%$ respectively) towards the stress level of the participants. This indicates that these factors were largely responsible for causing academic stress among the respondents.

Social Stress: The social stressors included were attending social events, trouble getting along with a family member, mingling with friends from other cultures, having no friends. It is obvious that a very small group (3.5 percent males and 1.5 percent females always had problem getting along with family members. A very small percentage of male $(1.3 \%)$ and female $(1.7 \%)$ participants did not have friends. The findings above suggest that social stress was not a concern for most of the participants.

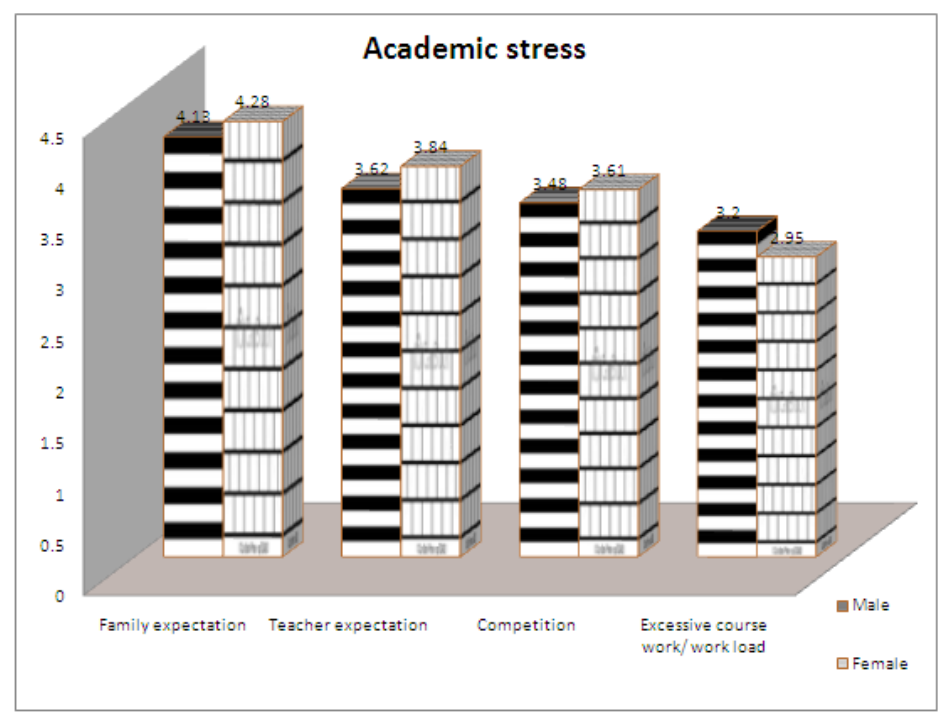

Fig.1. Academic Stressors of the Selected Participants

Emotional Stress: The most important emotional stressors included were adjusting and managing romantic relationship, things are not going along the way one wants them to, not feeling confident about oneself, feeling lonely, anxious and having no one to turn to and understand. Factors like things are not going along the way you want them to, not feeling confident about yourself, feeling lonely and anxious, and having no one to turn to and understand, the response was sometimes and there was a marginal difference in the responses of both males and females.

This result gives a good reflection of the emotional well being of the respondents

Financial Stress: The most important financial stressors included were not getting financial support from family for pursuing studies, parents control the money spent, trouble managing a budget, insufficient money for paying personal mobile and internet expenses.

Majority (26.4 percent males and 35 percent females) of the participants were having a sound financial background as their families were able to support them for pursuing their study. 
Positive Coping: Of the positive coping strategies, the mean scores reflected that meditation and prayer was the most effective for both gender followed by listening to music or watching television, sleep, pursuing hobby or interest, talking to parents or any family members and exercise or yoga respectively.

Negative Coping: Irrespective of the type of negative coping strategy (i.e., spending more time on social networking sites, smoking, taking alcohol and using drugs) it was revealed that males were more inclined to use these coping strategies than females.
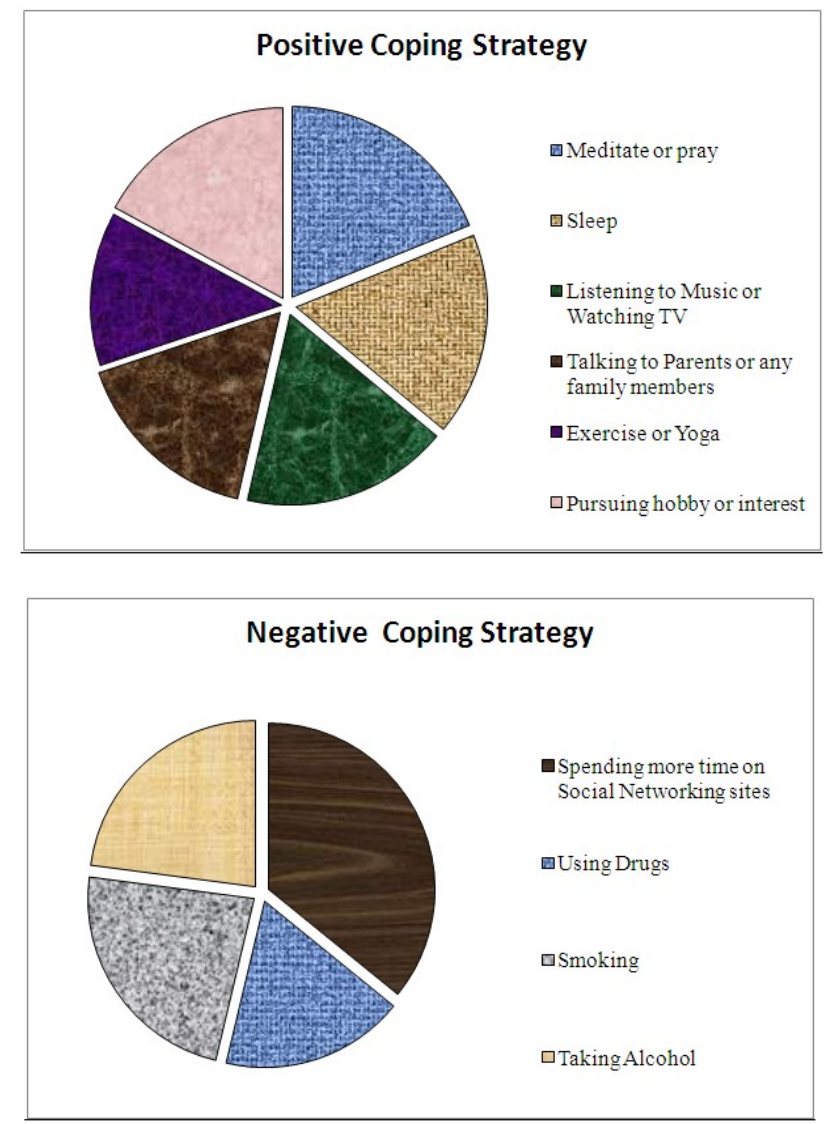

Fig - 2: Positive and Negative coping strategies of the participants

Inter-Relationship between Academic Stress and the Other Stressors: It was found that academic stress had a high degree of correlation with social stress and financial stress. Thus, it can be explained that if students had high academic stress, they were not able to socialize or if students were having problems socializing, their academic performance would be affected. It can also be interpreted that if students had financial stress their performance was expected to decline.

There is no significant co-relation (.071) between academic stress and behavior of the selected subjects, therefore it can be inferred that there is no relation between how the students expressed as behaviours when academically stressed.

Raychaudhuri et al., (2010) also found out that family income, class attendance, parent's education, student - teacher ratio, availability of skilled teachers in school, gender and the time taken to travel to the school campus also has an impact on the academic achievements of the student.

Table I Inter-Relationship Between Academic Stress And The Other Stressors

\begin{tabular}{|l|l|l|l|}
\hline Stress & $\begin{array}{l}\text { Social Stress } \\
\text { 'r' value }\end{array}$ & $\begin{array}{l}\text { Emotional Stress } \\
\text { 'r' value }\end{array}$ & $\begin{array}{l}\text { Financial Stress } \\
\text { 'r' value }\end{array}$ \\
\hline Academic Stress & $0.170^{* *}$ & 0.056 & $0.212^{* *}$ \\
\hline
\end{tabular}

**. Correlation is significant at the 0.01 level (2-tailed).

*. Correlation is significant at the 0.05 level (2-tailed). 
Association of Academic Stress with Coping Strategies of the Selected Participants: Positive coping strategies like prayers, meditation and sleep proved to be very effective if they had academic stress. There was a high degree of correlation between the coping strategies like meditation, prayer, sleep and academic stress. It was also found that students having academic stress did pursue hobbies and interest as a coping strategies and this was significant at 0.05 level. Academic stress was negatively correlated with coping mechanism like listening to music or watching television and negative coping strategies like using drugs/ smoking or taking alcohol. This means that these coping strategies might not have been helpful when these students experienced academic stress.

In a study conducted by Stewart et al.,(1997), psychological problems are lower in students with good coping skills. Coping mechanisms like counseling, meditation, sharing problems with friends, sound sleep and exercise were found to be helpful during stressful situation. The findings of the study revealed counselling as the best coping techniques in students.

Table II Association Of Academic Stress With Coping Strategies Of The Selected Participants

\begin{tabular}{|l|l|l|}
\hline SI no. & \multicolumn{1}{|c|}{ Coping strategies } & Academic stressors ' $r$ ' value \\
\hline & Positive coping & \\
\hline 1. & Meditate and pray & $0.112^{* *}$ \\
\hline 2. & Sleep & $0.129^{* *}$ \\
\hline 3. & Listening to music / watching T.V. & -0.014 \\
\hline 4. & Talking to Parents/ family members & 0.074 \\
\hline 5. & Exercise/yoga & -0.009 \\
\hline 6. & Hobby/interest & $0.091^{*}$ \\
\hline & Negative Coping & \\
\hline 1. & Spending time on social networking sites & 0.055 \\
\hline 2. & Using drugs & $-0.087^{*}$ \\
\hline 3. & Smoking & -0.057 \\
\hline 4. & Alcohol & -0.022 \\
\hline
\end{tabular}

**. Correlation is significant at the 0.01 level (2-tailed).

*. Correlation is significant at the 0.05 level (2-tailed).

\section{Stress levels of the participants as per the students stress scale}

The stress levels of the participants were found out after the administration of the students stress scale (Akhtar, 2004). Majority (38.9\%) of the participants (i.e., $15 \%$ males and $23.9 \%$ females) were experiencing very low stress. Only 11.9 per cent males were having very high stress whereas only 6.9 percent of females belonged to this category.

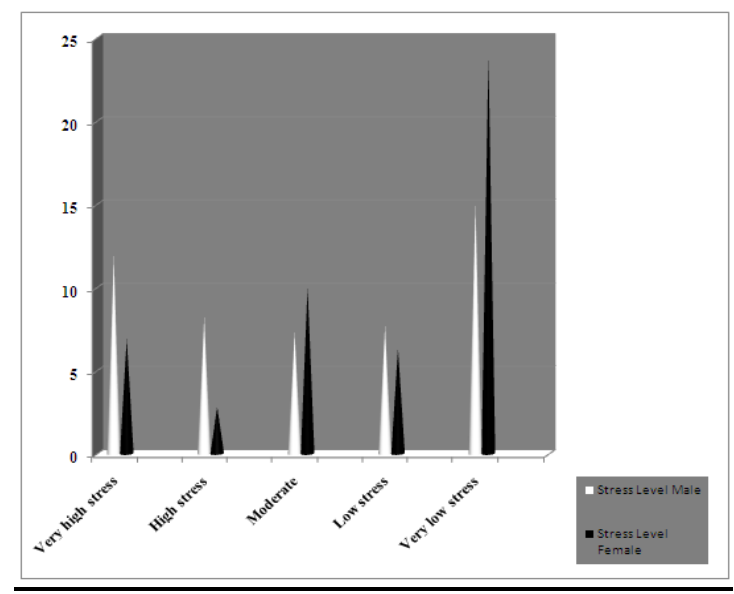

Fig-3: Stress levels of the selected participants

\section{Conclusion}

The main findings of this study therefore concluded that academic stress was highly correlated with social and financial stress. Likewise, the present study is also supported by studies conducted by Pinto et al. (2001); Dennis et al., (2005) and Nicpon et al., (2006) ; Raychaudhuri et al., (2010), Mehta, et al., (2011). Positive coping strategies like meditation, prayer and sleep was found to be very helpful (significant at 0.05 level) to combat academic stress. Pursuing hobbies and interest help students to cope with academic stress and these values were significant at 0.05 level. The study also found out that academic stress was negatively 
correlated with coping strategies like using drugs and this was significant at 0.05 level. During the period of the study, majority $(38.9 \%)$ of the participants were experiencing very low stress.

Limitations and Recommendations: Since the study was conducted at the beginning of the academic session, therefore the stress level of the students was found to be very low. Further research need to be conducted at the peak of the academic session in order to attain a clear picture. More studies can be conducted with a larger sample size.

\section{References}

[1]. Babar T. S., Kahloon, A., Kazmi, M., Khalid, H., Nawaz, K., Khan, N.A., and Khan,S. (2004). Students, Stress and Coping Strategies: A Case of Pakistani Medical School Community Health Sciences Department, Aga Khan University (AKU), Karachi, Pakistan Education for Health, 17( 3), 346-353.

[2]. Barber, B. \& Olsen, J. (2004). Assessing the transitions to middle and high school. Journal of Adolescent Research, 19, 4-23.

[3]. Blake, R.L., \& Vandiver, T. A. (1988). The association of health with stressful life changes, social supports, and coping. Family Practice Research Journal, 7 (4), pp. 205-218.

[4]. Campbell, R.L., and Svenson, L.W. (1992). Perceived level of stress among university undergraduate students in Edmonton, Canada. Perceptual and Motor Skills, Vol 75, 552-554.

[5]. Chew-Graham, C.A., Rogers, A., \& Yassin, N. (2003) "I would not want it on my CV or their records": Medical students' experiences of help seeking for mental health problems. Medical Education, 37,873-80

[6]. Conner, J., Pope, D., \& Galloway, M. (2009/2010). Success with Less Stress. Educational Leadership, 67 (4), $54-57$.

[7]. Dennis, J. M., Phinney, J. S., \& Chuateco, L. I. (2005). The role of motivation, parental support, and peer support in the academic success of ethnic minority first-generation college students. Journal of College Student Development, 46, 223-236. DOI: 10.1353csd.2005.0023.

[8]. Donaldson, D., Prinstein, M.J., Danovsky, M., \& Spirito, A. (2000). A pattern of children's coping with life stress: Implications for clinicians. American Journal of Orthopsychiatry, 70 (3), pp. 351-359.

[9]. Elizabeth Scott, M.S. (2009). Stress in College. Common Causes of Stress in College, Lambert Academic Publishing.

[10]. Everley, G, Jr., Lating, J. A. (2002). Clinical Guide to the Treatment of the Human Stress Response, 2nd Ed. New York: Kluwer Academic/Plenum Publishers

[11]. Feld, L.D. (2011). " Student Stress in High--Pressure College Preparatory Schools" Class of 2011, A thesis submitted to the faculty of Wesleyan University in partial fulfillment of the requirements for the Degree of Bachelor of Arts with Departmental Honors in Psychology Middletown, Connecticut.

[12]. Fish, C. \& Nies, M.A. (1996). Health promotion needs of students in a college environment. Public health Nursing, $13,104-111$.

[13]. Greenberg, J. S (1996). Comprehensive stress management (5th ed.), Chicago: Brown \& Benchmark.

[14]. Greenberg, S. F., \& Valletutti, P. J. (1980). Stress \& helping professions. Baltimore: Paul H. Brookes.

[15]. Krishnakumar, P., Geeta, M.G., Gopalan, A.V. (2005). Deliberate self-poisoning in children. Indian Journal of Pediatrics, 42(58), 2-6.

[16]. Lai, K.Y., Wong, C.K. (1992). Adolescent suicide attempts: A review. Journal of Hong Kong Medical Association, 44,139-45.

[17]. Lazarus, R. (1999). Stress and Emotion: A New Synthesis. London: Free Association Books. R.S. Lazarus. ISBN 1-85343-456-6.

[18]. Lazarus, R., Folkman, S. (1984). Stress, Appraisal and Coping. New York: Springer.

[19]. Lukoye A., Prisca A.M., Moses N.N., Kiende C.K \& Evans M.O (2011). Prevalence of substance use among college students in Eldoret, western Kenya BMC Psychiatry, 11:34. doi:10.1186/1471-244X-11-34

[20]. Maheshwari, K. U., \& Deepa, M. (2013). A Research Study on the Impact of Stress upon the Academic Performance of B-School Students, KCT Business School, Coimbatore.

[21]. Manjula, G., Kadapatti. \& Vijayalakshmi. (2012). "Stressors of Academic Stress: A study on pre-university students" .Indian. J. Sci. Res. 3(1): 171-175, 2012.

[22]. Mehta, S. S., Newbold, J. J., \& O'Rourke, M. A. (2011). Why do first-generation students fail? College Student Journal, 45(1), 2035.

[23]. Nicpon, M., Huser, L., Blanks, E., Sollenberger, S., Befort, C., \& Kurpius, S. (2006). The relationship of loneliness and social support with college freshmen's academic performance and persistence. Journal of College Student Retention: Research, Theory, and Practice, 8, 345-358.

[24]. Otieno A.O \& Ofulla A.V.O. (2009). Drug abuse in Kisumu town western Kenya. African Journal of Food, Agriculture, Nutrition and Development. 9, 846-858.

[25]. Patel D.R., Greydanus D.E., (1999). Substance Abuse: a Pediatric Concern. Indian Journal of Pediatrics. 66:557-567.

[26]. Pinto, M. B., Parente, D. H., and Palmer, T. S. (2001). College student performance and credit card usage. Journal of College Student Development, $42(1), 49-58$.

[27]. Ragheb, K.G., \& McKinney, J. (1993). Campus recreation and perceived academic stress. Journal of College Student Development, 34, pp. 5-10.

[28]. Raychaudhuri, A., Debnath, M., Sen, S., \& Majjumdar, B.G. (2010). "Factors affecting students' academic performance: A case study in Agartala municipal council area". Bangladesh-e-journal of Sociology, 7, (2).

[29]. Ross, S. E., Niebling, B. C., and Heckert, T. M (1999). Sources of stress among college students. College Student Journal, 33, 312318 .

[30]. Shaikh, B.T., Kahloon A., Kazmi, M., Khalid, H., Nawaz Khan, N.A. (2004). Stress management in medical students. Journal of college Physicians Surgeons, 14, 306.

[31]. St. John, E. (1998). Loan debt: A new view. Black Issues in Higher Education, 15(10), 16.

[32]. Stewart, S. M., Beton, C., Lan, T. H., Marshallk, I. B., Lee, P.W., Wong, C.M. (1997). Predicting stress in first year Medical students: a longitudinal study. Med Educ; 31, pp.163-8

[33]. Trockel, M. T., Barnes, M. D., \& Egget, D. L. (2000). Health-related variables and academic performance among first-year college students: Implications for sleep and other behaviors. Journal of American College Health, 49,125-140.

[34]. Verma, S., Sharma, D., Larson, R.W. (2002). School stress in India: Effect on time and daily emotions. International journal of Behavioural Development, 26, 500-8.

[35]. Wills, T. A. (1991). Similarity and self-esteem in downward comparison. In Sulus, J. And Wills, T. A. (Eds.), Social Comparison: Contemporary Theory and Research, Lawrence Erlbaum Associates, Hillsdale, NJ, pp. 51-78.

[36]. Womble, L.P. (2003). Impact Of Stress Factors On College Students Academic Performance University of North Carolina at Charlotte Undergraduate. Journal of Psychology. 16- 21. 